\title{
BMJ Open What risks to sustainability are identified throughout care bundle implementation and how can they be addressed? A mixed methods case study
}

\author{
Laura Lennox (D) ,1,2 Linda Eftychiou, ${ }^{3}$ Dionne Matthew, ${ }^{3}$ Jackie Dowell, ${ }^{4}$ \\ Trish Winn ${ }^{4}$
}

To cite: Lennox L, Eftychiou L, Matthew $\mathrm{D}$, et al. What risks to sustainability are identified throughout care bundle implementation and how can they be addressed? A mixed methods case study. BMJ Open 2021;11:e048815. doi:10.1136/ bmjopen-2021-048815

- Prepublication history and additional supplemental material for this paper are available online. To view these files, please visit the journal online (http://dx.doi.org/10.1136/ bmjopen-2021-048815).

Received 11 January 2021 Accepted 07 May 2021

Check for updates

(C) Author(s) (or their employer(s)) 2021. Re-use permitted under CC BY-NC. No commercial re-use. See rights and permissions. Published by BMJ.

${ }^{1}$ Department of Primary Care and Public Health, Imperial College London, London, UK ${ }^{2}$ National Institute for Health Research, Applied Research Collaboration Northwest London (ARC NWL), London, UK

${ }^{3}$ Strategy Department, Guy's and St Thomas' NHS Foundation Trust, London, UK

${ }^{4}$ Department of Research and Development, London North West University Healthcare NHS Trust, Harrow, UK

Correspondence to

Dr Laura Lennox;

l.lennox@imperial.ac.uk

\section{ABSTRACT}

Objectives Despite national guidance on how to identify and treat heart failure (HF), variation in HF care persists across UK hospitals. Care bundles have been proposed as a mechanism to deliver reliable optimal care for patients; however, specific challenges to sustain care bundles in practice have been highlighted. With few studies providing insight into how to design or implement care bundles to optimise sustainability, there is little direction for practitioners seeking to ensure long-term impact of their initiatives. This study explores the sustainability risks encountered throughout the implementation of a HF care bundle (HFCB) and describes how these challenges were addressed by a multidisciplinary team (MDT) to enhance sustainability over time.

Design A longitudinal mixed method case study examined the HFCB improvement initiative from September 2015 to August 2018. A standardised sustainability tool was used to collect perceptions of sustainability risks and actions throughout the initiative. Observations, keyinformant interviews and documentary analysis were conducted to gain in-depth understanding of how the MDT influenced sustainability through specific actions. A qualitative database was developed using a consolidated sustainability framework to conduct thematic analysis. Sustainability outcomes were explored 1-year post funding to ascertain progress towards sustainment.

Results The MDT identified six sustainability challenges for the HFCB: infrastructure limitations, coding reliability, delivery consistency, organisational fit, resource stability and demonstrating impact. The MDT undertook multiple actions to enhance sustainability, including: (1) developing a business case to address infrastructure limitations; (2) incorporating staff feedback to increase bundle usability; (3) establishing consistent training; (4) increasing reliability of baseline data; (5) embedding monitoring and communication; and (6) integrating the bundle into current practices.

Conclusion Through the description of challenges, actions and learning from the MDT, this study provides practical lessons for practitioners and researchers seeking to embed and sustain care bundles in practice.

\section{INTRODUCTION}

Heart failure (HF) is a rising global epidemic affecting 26 million people worldwide,
Strengths and limitations of this study

- The longitudinal nature of the study provided a rich environment for in-depth investigation of how sustainability of a heart failure (HF) care bundle is supported and achieved over time.

- A limitation of case study research is the extent to which generalisations can be drawn from single cases; probability that data are representative of other HF or care bundle initiatives cannot be established.

- Although the findings may not be directly transferable, they provide valuable insight into the types of actions needed to sustain care bundles, which can be considered and tested by future initiatives and research studies.

and more than half a million people in the United Kingdom (UK). ${ }^{12}$ It consumes up to $2 \%$ of the total NHS budget expenditure in its management and is the leading cause of hospital admission for people over 65 years of age. ${ }^{34}$ The National Institute for Health and Care Excellence (NICE) has published guidelines for the diagnosis and management of acute HF with specific recommendations. ${ }^{4}$ Despite national guidance on how to identify and treat the condition, variation in the organisation of HF services and clinical care persists across hospitals in the UK. Some of this variation exists due to the lack of access to key diagnostic tests, variation in patient characteristics and differences in symptom presentation to hospital. ${ }^{4}$ While specific evidence-based strategies (brain natriuretic peptide (BNP) test, echocardiogram and specialist input for diagnosis and management) have been found to reduce readmission rates for $\mathrm{HF}$ patients, these interventions deemed as 'gold standard' encounter challenges in their application and consistent delivery in the real-world practice. ${ }^{5}$ Lack of sustainability of best practice care for $\mathrm{HF}$ 
poses a significant risk, as chronic conditions require continuous and consistent care for optimal improvements in patient outcomes.

Care bundles have been proposed as a mechanism to deliver sustained optimal care for patients. ${ }^{6}$ This approach promotes attention to a core set of accepted elements of care, improving reliable delivery of recommendations. ${ }^{6}$ While a care bundle approach has been implemented within several HF studies, each has highlighted specific challenges encountered to sustain improvements once funding has ended. ${ }^{7-10} \mathrm{~A}$ small number of studies have suggested potential facilitators to sustaining care bundles such as instituting a culture of patient safety and promoting measurement of compliance data. ${ }^{9} 11-14$ However, these studies include only high-level descriptions of sustainability issues, often made retrospectively (after the initiative has either sustained or failed to sustain). ${ }^{15}$ Therefore, they do not provide insight into how to plan for, design, or implement a care bundle to optimise chances of long-term success. ${ }^{11} 1216$ With few studies focusing on actions and strategies to sustain, there is little direction or practical advice for researchers and practitioners seeking to influence sustainability of their care bundle initiatives. ${ }^{17-19}$

\section{Unpacking the 'process of sustaining'}

Sustainability, it is often viewed as an outcome or state to be reached at the end of implementation. ${ }^{20-22}$ However, it is increasingly recognised that implementation is rarely linear, often ending with varying degrees of implementation success. ${ }^{23}$ This has led many to recognise that in order to achieve sustainable improvements, actions and planning for sustainability must start during initiative implementation. ${ }^{212526}$ This has promoted a second perspective, which views sustainability as a dynamic process. $^{21}{ }^{27}$ There is no common description of what the 'process of sustaining' entails but it can be broadly defined as, the process by which individuals or teams plan for, and act, to embed initiatives and enhance continuation of initiative benefits, outcomes and practices. ${ }^{25} 28$ This can include any activities undertaken to influence sustainability before, during or after implementation. Providing evidence on what specific actions take place during this process and how they enhance sustainability is key in understanding how future initiatives can be designed and supported to optimise longterm success. ${ }^{17-19} 2930$

\section{Aims}

The purpose of this paper is to explore how a multidisciplinary team (MDT) planned for and influenced the sustainability of an HF care bundle (HFCB). This work will explore the sustainability challenges encountered throughout implementation and how these issues were addressed by the MDT to enhance sustainability over time. The following research questions will be investigated:
1. What risks to sustainability were identified throughout implementation of the HFCB and how were they addressed?

2. What lessons can be shared with other MDTs on how to embed and sustain care bundles?

\section{METHODS}

A longitudinal mixed methods case study was conducted to examine the HFCB improvement initiative from September 2015 to August 2018. The case is described in table 1.

Patient and public involvement: a patient representative was involved throughout the HFCB initiative as part of the MDT. The representative attended initiative meetings and fed into the design and delivery of the care bundle (eg, giving advice on how to engage HF patients with the bundle). The representative was also involved in the design and conduct for this study through advising on the research topic and research questions (eg, through describing personal health experiences and encounters with acute care) but was not involved in the reporting or dissemination plans of this research. Findings were shared with participants at initiative meetings and through summary reports.

\section{Data collection}

A structured sustainability tool, the Long Term Success Tool (LTST) (online supplemental appendix 2), was filled out quarterly by the MDT throughout the funded initiative (January 2016-April 2017) to collect perceptions of 12 sustainability factors. ${ }^{31}$ Responses from the tool measured ongoing performance against the factors and provided a mechanism to understand where to focus initial exploration of the qualitative data.

Non-participant observation of the MDT took place at facilitated workshops and routine meetings $(n=24$ hours) to identify how the team planned and took action to sustain their initiative. Observations were recorded in a field notebook and specific meetings were also audio recorded (eg, review meetings). Documentary analysis examined initiative materials (minutes of team meetings, presentations and programme review reports) to investigate achievements and challenges encountered and identify actions (planned and/or executed) related to sustainability.

Two rounds of key informant interviews were conducted by the lead author to gain in-depth understanding of sustainability planning as well as triangulate data from observations and document analysis. A purposive sampling strategy was used to recruit interviewees, with participants selected based on their role in the MDT (online supplemental appendix 3 Interviewee roles and Interview Guides).$^{32}$ The first round took place at the end of the 18-month funding period $(n=4)$ and the second revisited participants 1 year later to examine initiative progression $(n=4)$. Interviews were audio recorded and professionally transcribed. To assess progress towards 
Table 1 Case description

The case: heart failure (HF) care bundle multidisciplinary team (MDT)

\begin{tabular}{|c|c|c|}
\hline Background & \multicolumn{2}{|c|}{$\begin{array}{l}\text { A HF MDT at an acute hospital experienced ongoing challenges in delivering high-quality HF } \\
\text { care. This was highlighted in their National Heart Failure Audit data for } 2013 / 2014 \text {, which showed } \\
\text { that the Trust was performing below the national standard for specialist review and diagnostic } \\
\text { assessment outside of the cardiology ward }{ }^{66}\end{array}$} \\
\hline Initiative aim & \multicolumn{2}{|c|}{$\begin{array}{l}\text { To improve the health, quality of life and experience of care for patients who are primarily } \\
\text { diagnosed with acute HF }\end{array}$} \\
\hline Intervention & \multicolumn{2}{|c|}{$\begin{array}{l}\text { HF admissions care bundle comprising of three elements recommended in the National Institute } \\
\text { for Health and Care Excellence guidelines }{ }^{4} \text { (online supplemental appendix } 1 \text { ): } \\
\text { 1. Adults presenting to hospital with new/suspected acute HF have a single measurement of } \\
\text { natriuretic peptide. } \\
\text { 2. Adults admitted to hospital with new/suspected acute HF and raised natriuretic peptide levels } \\
\text { have a transthoracic Doppler two-dimensional echocardiogram within } 48 \text { hours of admission. } \\
\text { 3. Adults admitted to hospital with acute HF have input within } 24 \text { hours of admission from a } \\
\text { dedicated specialist HF team. }\end{array}$} \\
\hline The MDT and roles & $\begin{array}{l}\text { Consultant cardiologist (clinical lead): led } \\
\text { the discussion around changes to care and } \\
\text { suggestions for how to get other clinicians on } \\
\text { board } \\
\text { Registrar: helped drive home the message to } \\
\text { Junior doctors } \\
\text { HF nurse specialists: key to delivery of the } \\
\text { bundle and encouraged colleagues to complete } \\
\text { QI programme manager (project manager): } \\
\text { facilitated data collection and putting up weekly } \\
\text { tallies on wards } \\
\text { Improvement science manager: QI support and } \\
\text { documentation } \\
\text { Patient representative: informed the design and } \\
\text { delivery of the care bundle and study }\end{array}$ & $\begin{array}{l}\text { Coding administrators: intermittently } \\
\text { assisted in clarifying how to maximise } \\
\text { coding of HF patients and highlight } \\
\text { bundle to coding colleagues } \\
\text { Cardiac physiologist: helped identify how } \\
\text { to regularly record time echocardiogram } \\
\text { was done-as this was not regular } \\
\text { practice } \\
\text { Ward matrons: regular contact with } \\
\text { ward matrons helped facilitate constant } \\
\text { dialogue around HF bundle numbers and } \\
\text { highlight key areas of the bundle that } \\
\text { were not completed at any given time }\end{array}$ \\
\hline
\end{tabular}

sustainability, specific sustainability outcomes were assessed at follow-up. ${ }^{33}$

\section{Data analysis}

LTST ratings were input into an excel database and descriptive analysis performed. A qualitative database was then developed using NVivo V.10 to conduct thematic analysis. ${ }^{34-36}$ Interview transcripts, documents and observation fieldnotes were imported into the database. A preliminary coding structure was deductively developed, using the Consolidated Framework for Sustainability Constructs in Healthcare. ${ }^{37}$ The coding structure was iteratively refined as data were added. ${ }^{38}$ This process allowed for the development of themes specific to the research questions on challenges, actions and learning to be derived. ${ }^{39}$ The data were then summarised to highlight reoccurring themes and perspectives to be explored. ${ }^{3640}$

\section{RESULTS}

Throughout the initiative, the MDT expressed a desire for the bundle to become an embedded process at the Trust. LTST results provided an overview of the perspectives of sustainability throughout the initiative's funded period and reflect the dynamic nature of risks and facilitators to the process of sustaining, which were observed throughout implementation (figure 1).

While the MDT reported areas of strength in factors 'Commitment to the Improvement' and 'Involvement A (involvement of oneself in the initiative)', 'Resources', 'Involvement B (involvement of stakeholders, patients, carers and the public)' and 'Evidence of benefits', demonstrated lower ratings throughout the initiative. Analysis of LTST comments, observation notes, documents and interview transcripts revealed six key challenges to the process of sustaining, which underpinned these ratings: infrastructure limitations, coding reliability, delivery consistency, organisational fit, resource stability and demonstrating impact. The MDT employed several actions to address these issues to ensure continued use of the bundle beyond the funded project timeframe. These challenges and actions are described below and summarised along with key learning in figure 2 . 


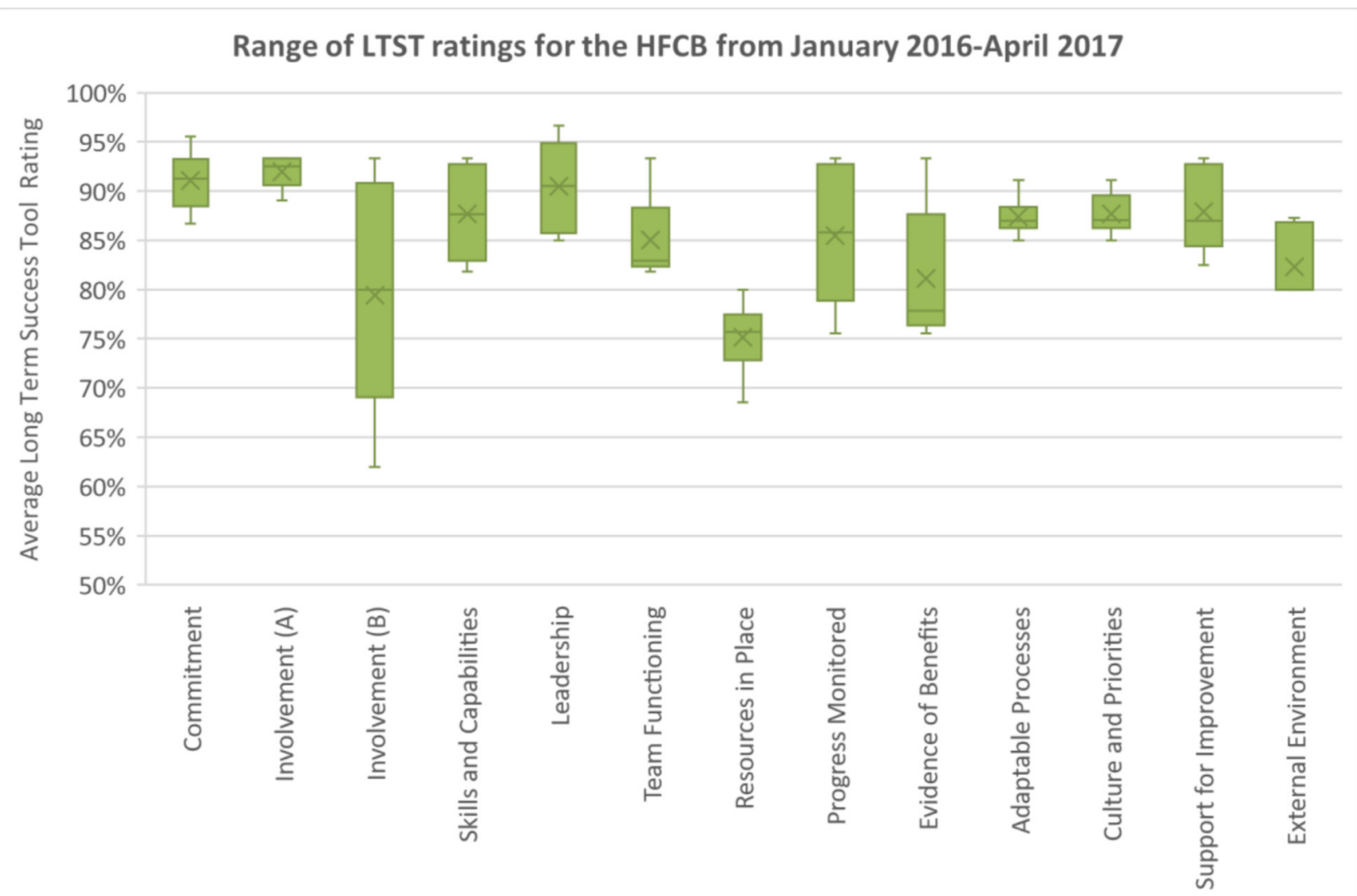

Sustainability Factors

Figure 1 Range of the Long Term Success Tool (LTST) ratings for the heart failure care bundle (HFCB) initiative taken quarterly between January 2016 and April 2017. The ratings show the dynamic range of sustainability risks and facilitators, which were observed throughout the HFCB implementation. X designates the average rating of each factor throughout the data collection period.

\section{Addressing process and infrastructure limitations}

Prior to the care bundle implementation, the MDT identified the need to understand and potentially change service processes and infrastructure to deliver the care bundle within the hospital. Two key issues were identified as potentially hindering bundle implementation and longevity: variability in care pathways and infrastructure limitations.

Variability in pathways for requesting echocardiograms in the current system, often increased the length of time for patients to receive an echocardiogram. The MDT also identified infrastructure limitations as they did not have enough echocardiogram machines to consistently perform echocardiograms within 48 hours of admission. In order to address these issues and ensure the bundle could be implemented to best practice standards, the team took several actions. First, the team designed a streamlined process to request echocardiograms and created a set of service standards for monitoring the echocardiograph completion times.

We did an overhaul of the echo pathway ... enabling us to do more echoes at the weekends ... which is part of the NICE guidelines for heart failure diagnosis for the hospital. (I5_Project Manager)
Second, the MDT developed a business case, outlining the inherent need and cost for more technicians and equipment to ensure patients could receive echocardiograms within the recommended timeframe. The business case was presented to senior leaders within the organisation and supported the team in obtaining additional funding from the Commissioning for Quality and Innovation (CQUIN) payment framework. ${ }^{41}$ This enabled the team to obtain four echocardiogram machines, which ensured this element of the bundle could be consistently delivered within the recommended timeframes beyond the initiative funded period. Addressing these process and infrastructure challenges at the beginning of the initiative provided the foundation for the HFCB implementation activities to be embedded within the Trust.

\section{Increasing bundle acceptability and usability}

A key challenge to sustaining this initiative was understanding how to incorporate staff preferences and fit the HFCB within the local hospital context. Without local fit, the MDT identified that the bundle would not be embraced or consistently used by staff.

The MDT took specific steps to understand the potential adaptations required to increase acceptability and usability of the bundle by making continuous efforts to 


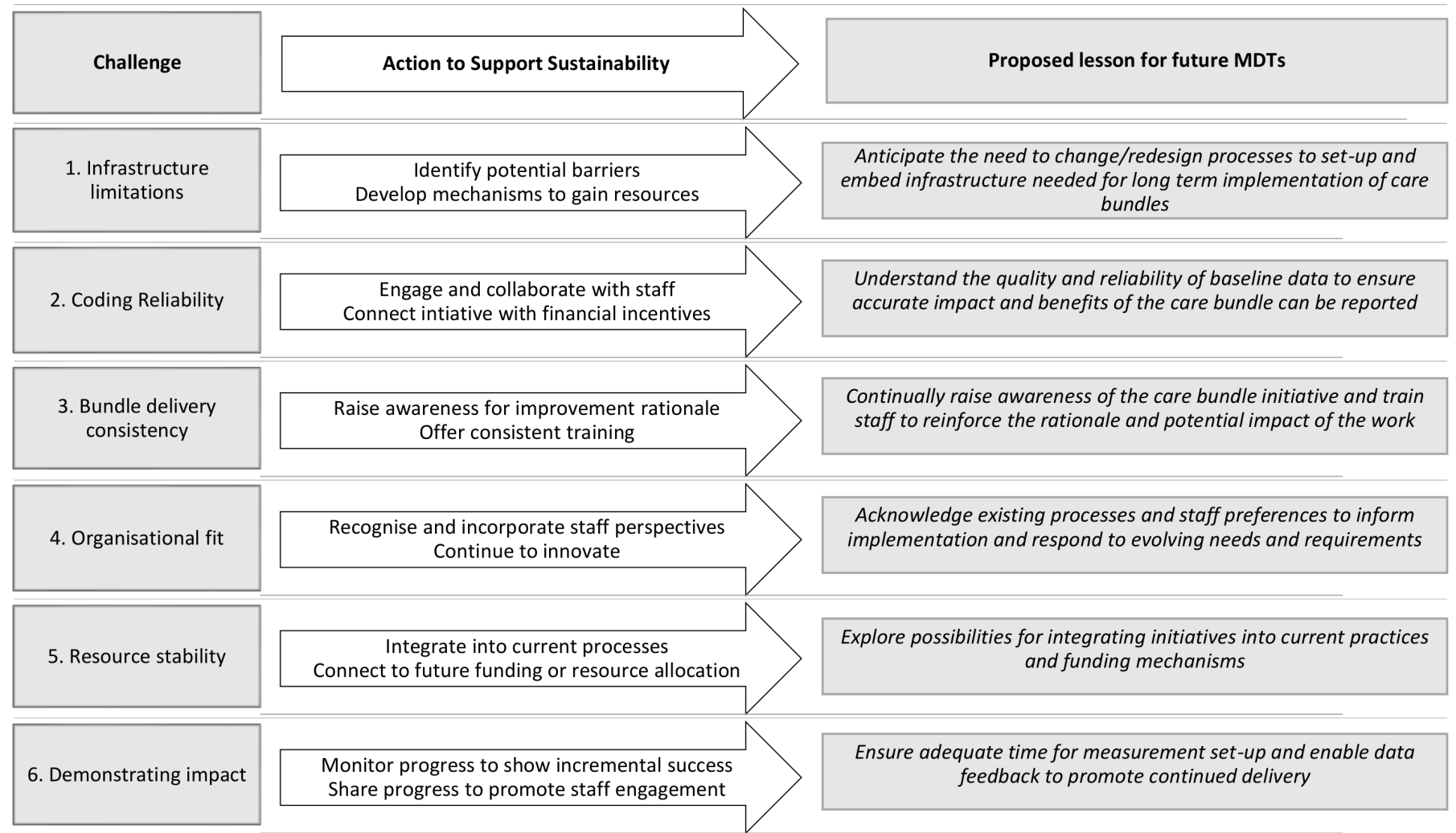

Figure 2 Summary of the challenges encountered, and actions taken by the multidisciplinary team (MDT) to support the process of sustaining along with proposed lesson for future MDTs.

document and act on staff feedback. For example, feedback resulted in changing the bundle to a 'sticker' format similar to other care bundles used within the hospital site. This ensured the bundle could be placed directly in the patient notes and fit with established local bundle practices. Staff also expressed a need for referral information and up-to-date guideline recommendations to be made available on the bundle forms, and this was included in updated versions.

We've now got a tick box that says, has the specialist nurse spoken to and/or given leaflets on heart failure to the patients? So that is an added bonus that we've made throughout the process of changing the versions. (I4_Data Analyst)

Responsiveness to staff preferences was noted as being necessary to the continued delivery of the bundle and contributing to the lasting implementation as the MDT was able to tailor processes and adapt the bundle to suit their local context.

\section{Establishing consistent training}

The MDT identified ongoing challenges related to implementation consistency and documentation of bundle element compliance. Participants specifically described how having reliable staffing to implement and document the bundle was a key challenge to sustainability throughout implementation.
You have turnover of junior doctors every six weeks ... so, again, just when you've got them comfortable and happy to use it then they change into another. So it's always going to be a challenge." (I1_QI manager)

The team took several actions to ensure staff were aware of the initiative and had the skills and capabilities to continually deliver the bundle in practice. The team conducted bi-weekly meetings to engage staff and ward managers in the bundle implementation. The team also built mechanisms such as induction packs and slides to train staff and new recruits on the bundle background and delivery. During training sessions, staff were regularly given feedback on bundle completion and compliance to maintain momentum for delivery. These actions to build awareness safeguarded the initiative for continued delivery beyond the funded period by enabling a wider workforce to deliver the bundle.

\section{Verifying reliability of baseline data}

Throughout initial implementation, the team identified several issues, which hindered understanding of the baseline diagnoses of HF patients within their organisation. Through weekly meetings and monitoring, the team noticed that despite the increased number of HFCBs being delivered, the number of patients coded with HF was not initially increasing. This issue was largely due to the accuracy of diagnostic coding. 
People are often coded wrongly for heart failure so even when they're looking at what the absolute number of people that should be on the bundle, it's always wrong. (I1, QI manager)

This issue was exacerbated by the inconsistent data within clinical notes, making the identification of patients admitted with HF in non-cardiology wards within the hospital very difficult. This meant that clinical coding for HF was not reliable, impacting the team's ability to accurately measure and report on the impact and benefits of the HFCB.

To address this issue, the team identified the average number of patients admitted with HF each month from the previous year. This provided the team with a rough target, which allowed them to meet and discuss barriers or issues if the numbers were lower than expected. Meetings were also conducted with the clinical coding team to clarify the necessity for appropriate coding and data accuracy as well as highlight ways to help coders identify HF patients. These meetings were used to share the rationale of the bundle, emphasising the impact on patient care and the need to meet a best practice tariff (BPT) for HF patients (the HF BPT is an incentive in secondary care in the UK to ensure patients with a confirmed diagnosis of $\mathrm{HF}$ are receiving specialist input. It requires providers to submit at least $70 \%$ of all eligible records and meet a target rate of $60 \%$ specialist input as recorded in the National Heart Failure Audit (NHFA)) ${ }^{42}$ Coding issues were recorded and logged each week allowing the team to monitor progress and patient notes were periodically selected for audit. These actions lead to improved collaborative working across the MDT and clinical coding team, improving accuracy of coding to ensure impact and benefits of the bundle could be reliably reported in the long term.

We monitor against our coding, so we know our coding's got better because obviously we've implemented the bundle and we sat down with Coding and they know what to look for in now. (I2_Service Manager)

\section{Embedding monitoring and feedback}

Providing timely evidence of benefits from the implementation of the HFCB was identified as a key challenge to sustainability. Measurement planning and set up took much longer than anticipated for the initiative as the team had to address underlying coding issues described above. These issues resulted in limited time to collect measures and perform summative evaluation of the HFCB.

The processes that they're trying to measure are real healthcare processes, they're messy, they're difficult to collect data from and so there were ... problems ... getting good data collection processes set up. (I6_ Data analyst)

This was seen as a key risk to sustainability because with little evidence of impact, the initiative would struggle to demonstrate value and garner ongoing support. Although the team struggled to produce evidence of the impact of the HFCB on patient outcomes during their funded period, they used several process measures to monitor progress and promote sustainability. Process measures (such as the number of bundles completed and the number of echocardiograms conducted within 48 hours) provided information to funders and organisational leaders to support continuation of the work.

Every clinical governance meeting we bring an update on what has happened and we use it to continually drive the bundle ... the constant reinforcement of data is helpful ...We just need to give them something to help keep them motivated. (I2, Service manager)

Sharing updates on progress enabled staff, managers and leaders to see incremental changes and improvements to the service and promoted continuous implementation of the bundle.

\section{Integrating into current practices}

Obtaining sustainable funding and staffing for the initiative were concerns for the MDT throughout implementation.

Staff and funding will always be an issue because everyone's stretched ... Everyone could use more staff and everyone could use more funding. (I2, Service manager)

In order to ensure continuation of the initiative within available resources, the team acknowledged the need to embed the initiative into current systems, processes and funding mechanisms where possible. As mentioned above, the team specifically created the HFCB to reflect the current bundle processes, which had been established by the hospital. This enabled the bundle to be seen as part of normal care processes and not additional workload.

Bundle design was consistent with other bundles that were in use at (the hospital), that system they had derived at through previous care bundles ... and it ended up working for this bundle as well. (I6, Data analyst)

The team also secured sustainable staffing for the delivery of the bundle by integrating the initiative into existing funding mechanisms, specifically the CQUIN payment framework programme and HF BPT.

We identified ... that if we could give evidence of meeting best practice, which is what the heart failure bundle is about, we would then get the tariff. So we've got now a process by which, we're ... almost bought in forever, because we're saying, well if you take this away, you're not going to get your best practice tariff, and in a cash strapped organisation, you can't afford for that to happen. (I5, Project Manager) 
The connection with the payment programmes gave the team a mechanism to integrate the initiative into existing funding streams to support its ongoing delivery. This allowed the team to monitor and deliver a standard of care while receiving payment for meeting specific targets.

The actions described above promoted sustainability for the HFCB and safeguarded its ongoing delivery. No single action was seen as being superior, but rather, the collective impact of multiple actions and systematic planning for sustainability was viewed as crucial in enhancing the chances of sustainability for the HFCB.

\section{IMPACT ON HFCB SUSTAINABILITY}

Initiative funding ended in April 2017 and follow-up interviews were conducted with the team in August 2018 to explore initiative progression and sustainability outcomes. The MDT expressed that the initiative was no longer viewed as a 'project' and the HFCB continued as regular practice at the hospital. The team described ongoing processes for bundle distribution and measurement. During the funded period (September 2015-April 2017), the MDT documented the completion of 1651 bundles. In the follow-up period (May 2017-August 2018), the bundle continued to be implemented with 1796 bundles completed during this time. The MDT also provided evidence demonstrating sustained improvement in the percentage of patients receiving echocardiogram, access to specialist input within the recommended timeframes and consistent BNP testing (figure 3).

The evidence for sustaining the HFCB is supported by previous work, which has demonstrated that each bundle element provides better care and outcomes for patients (eg, evidence shows in-hospital mortality outcomes for patients who access specialist care are better $(8.6 \%)$ in comparison to those who do not $(14.6 \%)) .{ }^{5}{ }^{43}$ Lack of sustainability of these best practices poses a significant risk for HF patients, as the condition requires continuous and consistent care for optimal patient outcomes. ${ }^{5}$ At follow-up, the team was in the process of conducting an evaluation to assess the bundle impact on re-admissions and mortality in this setting. These results are in preparation and will be published in a separate article. ${ }^{44}$

\section{DISCUSSION}

This study aimed to explore how an MDT planned for and influenced the sustainability of a HFCB. Findings provide insight into six sustainability challenges encountered throughout implementation and describe how these issues were addressed by the MDT to enhance sustainability over time.

It has been reported that implementing sustainable care bundles 'requires redesign of work processes, communication strategies and infrastructure, along with sustained measurement and vigilance'. ${ }^{6}$ This paper supports this assertion and demonstrates that in order to influence sustainability, the MDT were required to redesign care pathways, respond to staff and organisational needs, build relationships and collaborate across professional boundaries. A number of these actions have been supported in previous studies. ${ }^{92}{ }^{45-50}$ For example, continuous training and capacity building has been shown to strengthen project continuity and has been linked to maintaining initiatives in standard operating procedures. ${ }^{46-49}$ Similarly, integration of bundle initiatives into local processes and systems has also been supported by multiple studies. ${ }^{29} 460$ Green $e t a t^{45}$ found that integration of two care bundles

Figure 3 National Heart Failure Audit data from 2013/2014 to 2018/2019 for the hospital site showing the percentage of patients receiving echocardiogram, and specialist input within the recommended National Institute for Health and Care Excellence (NICE) guideline targets, and brain natriuretic peptide testing. ${ }^{4366-69}$ 
(chronic obstructive pulmonary disease and diabetic foot care) into routine clinical data systems was essential to embed change, thereby maximising the potential for sustainability.

In addition to corroborating previous findings, this work also builds new learning by describing the process of sustaining through the specific actions used by the MDT to address sustainability risks. ${ }^{17-19} 2930$ By providing insight into how, and why, these actions took place and describing their relationship with sustainability, this work responds to calls for better understanding of, and preparation for, the challenges associated with sustaining improvements in healthcare. Providing insight into the process of sustaining and how improvement teams promote continuation of improved practices and outcomes over time will aid future practitioners to enhance planning, design and support to optimise long term success. ${ }^{212751-53}$

\section{Implications for practitioners}

As well as the key learning proposed in figure 2, this work has highlighted three key areas for MDT and practitioner reflection to enhance learning for other initiatives.

1. Consider sustainability from the beginning: a common error of many improvement projects is thinking of sustainability only at the end of funding. ${ }^{54-56}$ This study has supported previous evidence that sustainability issues occur across all stages of implementation. ${ }^{15}$ The focus on sustainability early and throughout bundle implementation was a novel exercise for many of the MDT. The foresight provided by this perspective allowed the MDT to better anticipate emerging issues and address problems before they became major complications.

2. Combine top-down and bottom-up approaches: the importance of securing support from top management, while leaving room for practitioners to improve their own work processes, has been reported. ${ }^{57}$ In this study, management widely supported the need for best practice guideline adherence, but allowed the MDT to take ownership of the initiative and use their diverse expertise to design the bundle and organise its implementation. This combined approach allowed the initiative to align clinical guidelines with 'practical wisdom' and implementation 'know-how'. ${ }^{5} 59$

3. Use quality improvement tools to promote reflection and continual improvement: within this study, the LTST provided a mechanism to engage the MDT in ongoing reflection of the progress of their improvement initiative. Employing such tools can promote a culture of learning where identifying risks and making corrective action becomes the 'norm' enabling continual improvement to initiative design, implementation and measurement as well as consistent planning for the longevity of improvement efforts. ${ }^{60}$

\section{Strengths, limitations and future research}

The process of sustaining is missed in research studies reporting only continuity or discontinuity of improvements. ${ }^{61}$ This work provided a structured look at the
HFCB MDT's sustainability journey, describing the challenges and actions required to sustain in practice. The longitudinal nature of the study provided a rich environment for in-depth investigation of how sustainability is supported and achieved over time.

Although this study offers valuable insight, there are key limitations which should be considered. A limitation of case study research is the extent to which generalisations can be drawn from single cases. ${ }^{62}$ We cannot establish the probability that data is representative of other care bundle initiatives. Although the findings may not be directly transferable, they provide valuable insight into the types of actions needed to sustain, which can be considered and tested by future initiatives and research studies. The second limitation of this work is related to the timeframe of study. Although prospective investigation has been recommended in sustainability studies, this approach also creates some difficulty for researchers in choosing an appropriate timeframe for follow-up. ${ }^{63} 64$ This study was able to gather multiple snapshots of the process of sustaining and what was being 'sustained', but it was clear that this process would continue beyond this study. Future assessment would likely reveal further changes to the initiative and demonstrate new challenges encountered..$^{156365}$ Therefore, the potential time specific nature of any findings must be considered. ${ }^{25} 64$

While this study has outlined several key findings for sustainability and care bundle research, areas requiring further exploration have been recognised. For example, studying the application of these findings in further settings would provide valuable information on if, and how, these actions are used and what alternative strategies are identified. This learning would provide valuable information for future improvement work in terms of understanding pre-emptive actions to take to enhance sustainability and mitigate risks.

\section{CONCLUSION}

The majority of healthcare research focuses on initial implementation and adoption of interventions, with far less attention paid to the question of how to sustain beneficial or effective healthcare improvements. ${ }^{17}$ This paper aims to address this gap by providing insight into the actions which supported and enhanced sustainability of a HFCB. Through the description of challenges, actions and learning from the MDT, this study provides practical lessons for practitioners and researchers seeking to embed and sustain practices that improve patient care.

Twitter Laura Lennox @LauraLennox3, Linda Eftychiou @LindaEfty, Dionne Matthew @DMatthew9 and Trish Winn @trish_winn

Acknowledgements The authors would like to thank the participants of this research for agreeing to be involved and allowing access to their workplaces and daily activities. Their participation made these findings possible and their time, support and feedback were greatly appreciated. The research team also acknowledges the support of the National Institute for Health Research Clinical Research Network. The authors would also like to thank Ron Grant for his 
participation in the multidisciplinary team and sharing his experience to inform the design and conduct of this study.

Contributors LL conceived of the study. LL and DM conducted the observations and $L L$ conducted the interviews and documentary analysis. $L L$ and LE conducted the thematic analysis. DM, JD and TW reviewed and commented on themes and findings. LL drafted the first version of the paper and LE made contributions to interpret results and develop the conceptual findings of the paper. All authors contributed to the development of the manuscript content, and read and approved the final manuscript.

Funding This research was funded by the National Institute for Health Research Applied Research Collaboration Northwest London (NIHR ARC NWL).

Disclaimer This article presents independent research commissioned by the National Institute for Health Research (NIHR) under Applied Research Collaboration (ARC) programme for North West London. The views expressed in this publication are those of the author(s) and not necessarily those of the NHS, the NIHR or the Department of Health.

\section{Competing interests None declared.}

Patient consent for publication Not required.

Ethics approval This study complies with the Declaration of Helsinki, with approval from the NHS Health Research Authority (IRAS 188851). Although the potential for distress or risks for participants in this study was low, ethical considerations for consent, confidentiality and data protection were made. Participants were given information sheets about the study and consent forms prior to observations and interviews. All participants provided written consent prior to participation. Participants were also given the option to withdraw from the study at any time prior to write up. To ensure confidentiality, names of participants were not audio recorded during the interviews and each participant was assigned a unique identifier. All recorded and transcribed information as well as names and contact details were kept in separate, password protected files' stored secure servers. Access was only permitted to approved researchers. All data remained fully confidential and findings are reported in an aggregated manner without reference to individuals' names. To maximise confidentiality of individual participants, generic job titles such as doctor or nurse instead of specific grades or specialty titles have been used.

\section{Provenance and peer review Not commissioned; externally peer reviewed.}

Data availability statement All data relevant to the study are included in the article or uploaded as supplementary information.

Supplemental material This content has been supplied by the author(s). It has not been vetted by BMJ Publishing Group Limited (BMJ) and may not have been peer-reviewed. Any opinions or recommendations discussed are solely those of the author(s) and are not endorsed by BMJ. BMJ disclaims all liability and responsibility arising from any reliance placed on the content. Where the content includes any translated material, BMJ does not warrant the accuracy and reliability of the translations (including but not limited to local regulations, clinical guidelines, terminology, drug names and drug dosages), and is not responsible for any error and/or omissions arising from translation and adaptation or otherwise.

Open access This is an open access article distributed in accordance with the Creative Commons Attribution Non Commercial (CC BY-NC 4.0) license, which permits others to distribute, remix, adapt, build upon this work non-commercially, and license their derivative works on different terms, provided the original work is properly cited, appropriate credit is given, any changes made indicated, and the use is non-commercial. See: http://creativecommons.org/licenses/by-nc/4.0/.

\section{ORCID iD}

Laura Lennox http://orcid.org/0000-0002-8991-1702

\section{REFERENCES}

1 Ambrosy AP, Fonarow GC, Butler J, et al. The global health and economic burden of hospitalizations for heart failure: lessons learned from hospitalized heart failure registries. J Am Coll Cardiol 2014;63:1123-33.

2 Townsend N, Williams J, Bhatnagar P. Cardiovascular disease statistics, 2015. Available: https://www.bhf.org.uk/publications/ statistics/cvd-stats-2015

3 Braunschweig F, Cowie MR, Auricchio A. What are the costs of heart failure? Europace 2011;13 Suppl 2:ii13-17.
4 National Institute for Health and Care Excellence. Acute heart failure: diagnosing and managing acute heart failure in adults, 2014. Available: https://www.ncbi.nlm.nih.gov/books/NBK248063/ [Accessed 29 Jul 2019].

5 Wood RL, Migliore LA, Nasshan SJ, et al. Confronting challenges in reducing heart failure 30-day readmissions: lessons learned with implications for evidence-based practice. Worldviews Evid Based Nurs 2019;16:43-50.

6 Resar R, Griffin F, Haraden C. Using care bundles to improve health care quality. IHI Innov Ser white Pap 2012 www.IHI.org

7 LeMaster $\mathrm{CH}$, Hoffart N, Chafe T, et al. Implementing the central venous catheter infection prevention bundle in the emergency department: experiences among early adopters. Ann Emerg Med 2014;63:340-50.

8 Zafar MA, Nguyen B, Gentene A, et al. Pragmatic challenge of sustainability: long-term adherence to COPD care bundle maintains lower readmission rate. Jt Comm J Qual Patient Saf 2019;45:639-45.

9 Hakko E, Guvenc S, Karaman I, et al. Long-Term sustainability of zero central-line associated bloodstream infections is possible with high compliance with care bundle elements. East Mediterr Health $J$ 2015;21:293-8.

10 Thomas N, Gallagher H, Jain N. A quality improvement project to improve the effectiveness and patient-centredness of management of people with mild-to-moderate kidney disease in primary care. BMJ Qual Improv Rep 2014;3. doi:10.1136/bmjquality.u201337.w825. [Epub ahead of print: 2904 2014]. u201337.w8253.

11 Kim RY, Kwakye G, Kwok AC, et al. Sustainability and long-term effectiveness of the who surgical safety checklist combined with pulse oximetry in a resource-limited setting: two-year update from Moldova. JAMA Surg 2015;150:473-9.

12 Schwamm LH, Fonarow GC, Reeves MJ, et al. Get with the Guidelines-Stroke is associated with sustained improvement in care for patients hospitalized with acute stroke or transient ischemic attack. Circulation 2009;119:107-15.

13 Caserta RA, Marra AR, Durão MS, et al. A program for sustained improvement in preventing ventilator associated pneumonia in an intensive care setting. BMC Infect Dis 2012;12:1-8.

14 Lennox L, Green S, Howe C, et al. Identifying the challenges and facilitators of implementing a COPD care bundle. BMJ Open Respir Res 2014;1:e000035.

15 Shelton RC, Cooper BR, Stirman SW. The sustainability of evidencebased interventions and practices in public health and health care. Annu Rev Public Health 2018;39:55-76.

16 Pronovost PJ, Watson SR, Goeschel CA, et al. Sustaining reductions in central line-associated bloodstream infections in Michigan intensive care units: a 10-year analysis. Am J Med Qual 2016;31:197-202.

17 Buchanan D, Fitzgerald L, Ketley D, eds. The sustainability and spread of organisational change. Abingdon, Untied Kingdon: Routledge, 2007

18 Greenhalgh T, Robert G, Macfarlane F, et al. Diffusion of innovations in service organizations: systematic review and recommendations. Milbank Q 2004;82:581-629.

19 Damschroder LJ, Aron DC, Keith RE, et al. Fostering implementation of health services research findings into practice: a consolidated framework for advancing implementation science. Implement Sci 2009;4:50.

20 Savaya R, Elsworth G, Rogers P. Projected sustainability of innovative social programs. Eval Rev 2009;33:189-205.

21 Pluye P, Potvin L, Denis J-L. Making public health programs last: conceptualizing sustainability. Eval Program Plann 2004;27:121-33.

22 Lennox L. Implementation Sustainability. In: Nilsen P, Birkin S, eds. Handbook on implementation science. Cheltenham: Edward Elgar Publishing Ltd, 2020: 333-68.

23 Ham C, Kipping R, McLeod H. Redesigning work processes in health care: lessons from the National health service. Milbank $Q$ 2003;81:415-39.

24 Plsek PE, Greenhalgh T. Complexity science: the challenge of complexity in health care. BMJ 2001;323:625-8.

25 Scheirer MA, Dearing JW. An agenda for research on the sustainability of public health programs. Am J Public Health 2011;101:2059-67.

26 Maher L, Gustafson D, Evans A. Sustainability Model and guide. Coventry, UK: NHS Institute for Innovation and Improvement, 2010.

27 Brinkerhoff DW, Goldsmith AA. Promoting the sustainability of development institutions: a framework for strategy. World Dev 1992;20:369-83.

28 Johnson K, Hays C, Center $\mathrm{H}$. Building capacity and sustainable prevention innovations: a sustainability planning model. Eval Program Plann 2004:27:135-49. 
29 Martin GP, Weaver S, Currie G, et al. Innovation sustainability in challenging health-care contexts: embedding clinically led change in routine practice. Health Serv Manage Res 2012;25:190-9.

30 Szulanski G. Sticky knowledge: barriers to knowing in the firm. Thousand Oaks, California: Sage Publications, 2003.

31 Lennox L, Doyle C, Reed JE, et al. What makes a sustainability tool valuable, practical and useful in real-world healthcare practice? A mixed-methods study on the development of the long term success tool in northwest London. BMJ Open 2017;7:1-13.

32 Saunders MN. Choosing research participants. In: Symon G, Cassell C, eds. Qualitative organizational research: core methods and current. London: Sage Publications, 2012: 35-53.

33 Lennox L, Linwood-Amor A, Maher L, et al. Making change last? exploring the value of sustainability approaches in healthcare: a scoping review. Health Res Policy Syst 2020;18:1-24.

34 Braun V, Clarke V. Using thematic analysis in psychology. Qual Res Psych 2006;3:77-101.

35 Vaismoradi $\mathrm{M}$, Turunen $\mathrm{H}$, Bondas $\mathrm{T}$. Content analysis and thematic analysis: implications for conducting a qualitative descriptive study. Nurs Health Sci 2013;15:398-405.

36 Ritchie JS. Qualitative data analysis for applied policy research London: Routledge, 1994.

37 Lennox L, Maher L, Reed J. Navigating the sustainability landscape: a systematic review of sustainability approaches in healthcare. Implementation Sci 2018;13:1-17.

38 Elo S, Kyngäs $\mathrm{H}$. The qualitative content analysis process. J Adv Nurs 2008;62:107-15.

39 Pope C, Ziebland S, Mays N. Analysing qualitative data. BMJ 2000;320:114-6.

40 Ryan A. Methodology: analysing qualitative data and writing up your findings. Res Writ your thesis A Guid Postgrad students 2006:92-108 http://eprints.nuim.ie/871/

41 England NHS. Commissioning for quality and innovation. NHS Stand. Contract 2019;1.

42 NHFA and MINAP. Best practice tariff reporting guidance: using national audit data to develop validation reports; 2013.

43 National Institute for Cardiovascular outcomes research (NICOR). National heart failure audit. London; 2019.

44 Woodcock T, Matthew D, Palladino R. The effect of implementing a heart failure admission care bundle on hospital readmission and mortality rates: an interrupted time series study 2021.

45 Green SA, Bell D, Mays N. Identification of factors that support successful implementation of care bundles in the acute medical setting: a qualitative study. BMC Health Serv Res 2017;17:1-8.

46 Virani T, Lemieux-Charles L, Davis DA, et al. Sustaining change: once evidence-based practices are transferred, what then? Healthc $Q$ 2009;12:89-96.

47 Lehr JK, Rice RE. Organizational measures as a form of knowledge management: a multitheoretic, communication-based exploration. J. Am. Soc. Inf. Sci. 2002;53:1060-73.

48 Curry SJ, Mermelstein RJ, Sporer AK. Sustainability of communitybased youth smoking cessation programs: results from a 3-year follow-up. Health Promot Pract 2016;17:845-52.

49 Milne S, Greenaway S, Conway K, et al. What next? sustaining a successful small-scale alcohol consumption harm minimization project. Subst Use Misuse 2007;42:1933-44.

50 Reed JE, Howe C, Doyle C, et al. Simple rules for evidence translation in complex systems: a qualitative study. BMC Med 2018;16:1-20.
51 Proctor E, Luke D, Calhoun A, et al. Sustainability of evidencebased healthcare: research agenda, methodological advances, and infrastructure support. Implement Sci 2015;10:88.

52 Snowden DJ, Boone ME. A leader' S framework for decision making a leader' $S$ framework for decision making. Harv Bus Rev 2007;5:68-76.

53 NHS Modernisation Agency. Complexity of sustaining healthcare improvements: what have we learned so far? 2004.

54 Shediac-Rizkallah MC, Bone LR. Planning for the sustainability of community-based health programs: conceptual frameworks and future directions for research, practice and policy. Health Educ Res 1998:13:87-108.

55 Doyle C, Howe C, Woodcock T, et al. Making change last: applying the NHS Institute for innovation and improvement sustainability model to healthcare improvement. Implement Sci 2013;8:127.

56 Feldstein AC, Glasgow R, Practical A. Robust implementation for integrating research findings into practice. Jt Comm J Qual patient Saf 2008;34:228-43.

57 Hovlid E, Bukve O, Haug K, et al. Sustainability of healthcare improvement: what can we learn from learning theory? BMC Health Serv Res 2012;12:235.

58 Holmes BJ, Best A, Davies $\mathrm{H}$, et al. Mobilising knowledge in complex health systems: a call to action. evid policy 2017;13:539-60.

59 Dixon-woods M. The problem of context in quality improvement, 2014. Available: http://www.health.org.uk/publications/perspectiveson-context/

60 Lennox L, Reed J, French C. A qualitative exploration of sustainability processes for improvement: the role of structured sustainability tools. In: Nugus P, Rodriguez C, Denis J-L, eds. Transitions and boundaries in the coordination and reform of health services. Montreal: Palgrave Macmillan, 2020: 271-95.

61 Greenhalgh T, Robert G, Bate P. How to spread good ideas: a systematic review of the literature on diffusion, dissemination and sustainability of innovations in health service delivery and organisation 2004.

62 Eisenhardt KM, Graebner ME. Theory building from cases: opportunities and challenges. Acad Manage J 2007;50:25-32.

63 Wiltsey Stirman S, Kimberly J, Cook N, et al. The sustainability of new programs and innovations: a review of the empirical literature and recommendations for future research. Implement Sci 2012;7:17.

64 Bowman CC, Sobo EJ, Asch SM, et al. Measuring persistence of implementation: QUERI series. Implement Sci 2008;3:21.

65 Mclntosh K, Mercer SH, Nese RNT, et al. Predictors of sustained implementation of School-wide positive behavioral interventions and supports. J Posit Behav Interv 2016;18:209-18.

66 Cleland J, Dargie H, Hardman S. National heart failure audit: 20132014. Br Soc Hear Fail 2014:1-64.

67 Donkor A, Mcdonagh T, Hardman S. National heart failure audit April 2014-March 2015;2015.

68 NCAP National Cardiac Audi Programme. National HF audit 2016/17 summary report, 2017. Available: https://www.nicor.org.uk/wpcontent/uploads/2018/11/Heart-Failure-Summary-Report-2016-17. pdf

69 Donkor A, Hardman S, McDonagh T. National heart failure audit: April 2015 to March 2016. 2016;:1-71. Available: http://www.ucl.ac.uk/ nicor/audits/heartfailure/documents/annualreports/annual-report2015-6-v8.pdf 